Archived version from NCDOCKS Institutional Repository http://libres.uncg.edu/ir/asu/

\title{
Appalachlyan
}

B O O N E, NORT H CAROL I N A

\section{Linking Feedback Quality And Goal Orientation To Feedback Seeking And Job Performance}

\author{
Authors: \\ Whitaker, B., \& Levy, P
}

\begin{abstract}
:
Contemporary feedback researchers have adopted theoretical perspectives in which personal characteristics interact with aspects of the feedback environment to influence feedbackrelated perceptions, feedback seeking, and job performance. To test these assertions, this study incorpo-rates implicit person theory, uncertainty reduction theory, and Korman's theory of work motivation (2001) to develop a model that links a critical aspect of the feedback environment (feedback quality) and goal orientation to perceptions of feedback utility, feedback seeking, role clarity, and task performance and organizational citizenship behaviors. Results from supervisor-subordinate dyadic data $(\mathrm{N}=202)$ obtained from employed students largely support the hypothesized model. Implications are discussed.
\end{abstract}

Whitaker, B., \& Levy, P (2012) "Linking Feedback Quality And Goal Orientation To Feedback Seeking And Job Performance" Human Performance Version of Record Available At www.tandfonline.com [DOI: 10.1080/08959285.2012.658927] 


\section{INTRODUCTION}

In their seminal publication, Ashford and Cummings (1983) introduced the concept of feedbackseeking behavior and the notion of employees as active participants in the feedback process who seek feedback in an effort to reduce uncertainty about goal pursuit and appropriate process-related behaviors. Subsequent research has since demonstrated the value of feedback-seeking behavior to both the employee and the organization (Chen, Lam, \& Zhong, 2007; Lam, Huang, \& Snape, 2007; Whitaker, Dahling, \& Levy, 2007). However, scholars have noted that we still have an incomplete understanding of many important aspects of feedback-seeking behavior, particularly the influence of the feedback context (Ashford, Blatt, \& VandeWalle, 2003; Steelman, Levy, \& Snell, 2004), the joint impact of contextual and dispositional factors on the performance feedback encounter (Gregory, Levy, \& Jeffers, 2008; London \& Maurer, 2004), and the influence of feedback inquiry on performance (Ashford et al., 2003; Lam et al., 2007; Sessa \& London, 2006).

We address these gaps in the literature by developing and testing a model of context, personality, feedback seeking, and job performance (see Figure 1) with two goals in mind.

First,

Correspondence should be sent to Brian G. Whitaker, Appalachian State University, Department of Management, 4078 Raley Hall, Boone, NC 28607. E-mail: whitakerbg@appstate.edu 


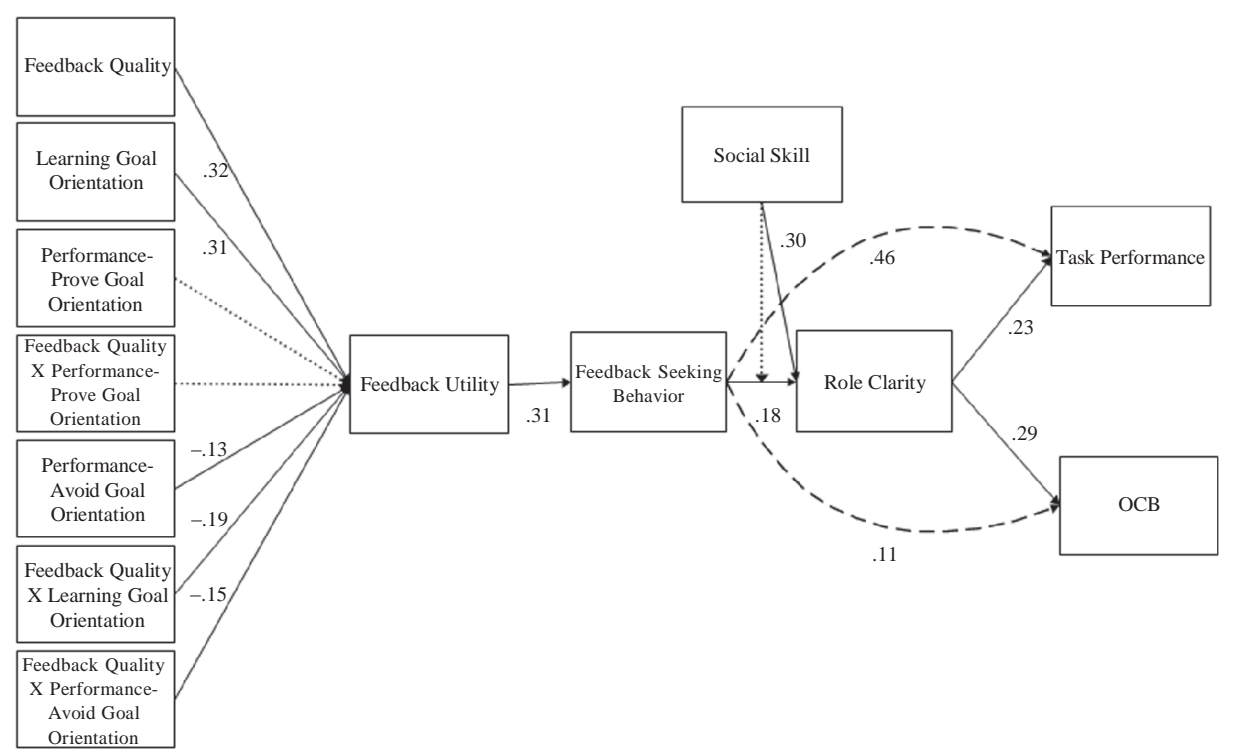

FIGURE 1 Model linking feedback quality to job performance through feedback utility, feedback seeking, and role clarity.

Note. Paths with no associated coefficient omitted from final path model estimation. All other paths significant. $\mathrm{OCB}=$ organizational citizenship behavior.

this study uses Korman's (2001) theory of work motivation to investigate the links between ambient feedback quality and feedback seeking. Specifically, we examine (a) the indirect effect of feedback utility on the relationship between feedback quality and feedback seeking, and (b) the influence of trait goal orientation on utility and its moderating influence on the relationship between feedback quality and feedback utility. Korman (2001) theorized that contextual elements of the workplace combine with dispositional factors to influence two independent self-regulatory processes - the self-enhancement motivational system and the self-protective motivational system. Consistent with this theory, we argue that contextual feedback quality gives rise to feedback utility out of self-enhancement concerns. Further, we integrate Korman's perspective with implicit person theory (Dweck \& Leggett, 1988; Tuckey, Brewer, \& Williamson, 2002; VandeWalle, 2003) to argue that trait goal orientation dictates which selfregulatory process dominates, thus influencing the extent to which feedback quality evokes feedback utility. Second, this study links the self-enhancement perspective with uncertainty reduction theory (Ashford et al., 2003; Taylor, Fisher, \& Ilgen, 1984) to more clearly elucidate the indirect relationship between feedback seeking and job performance. We hypothesize that feedback inquiry is indirectly associated with task performance and organizational citizenship behaviors (OCBs) through role clarity and that the feedbackseeking/role clarity link is moderated by social skill.

Ultimately, our study advances the feedback-seeking literature by drawing empirical links between feedback quality, disposition, and important individual and organizational outcomes consistent with theory. 


\section{FEEDBACK QUALITY, FEEDBACK UTILITY, AND FEEDBACK SEEKING}

High-quality feedback is specific, is consistent across time, and provides information on the specific goal-related behaviors and processes that result in performance outcomes (London, 2003; Steelman et al., 2004). Further, it is thought to influence employee behavior by providing diagnostic information on task-related errors and increasing attentional resources available for successful job performance (Kanfer \& Ackerman, 1989). Indeed, empirical evidence indicates that feedback augmented with supplemental information pertaining to the task, strategies, and appropriate task behaviors-that is, feedback high in quality-influences subsequent performance in a positive, monotonic manner (Kluger \& DeNisi, 1996).

Consequently, the feedback quality construct has emerged as a theoretically powerful contextual determinant of feedback-seeking behavior and is consistently emphasized in process models of feedback seeking and job performance (Gregory et al., 2008; London \& Maurer, 2004; Morrison, 2002). According to these models, the feedback environment in which an employee performs job-related behaviors regulates the extent to which employees engage others in feedback exchanges. Moreover, these theoretical perspectives postulate that aspects of the feedback context interact with broad personal characteristics to influence narrower, feedback-specific traits, which in turn affect how individuals engage in the feedback process. However, despite considerable theoretical work, empirical research investigating the mechanisms linking contextual feedback quality, personality, and proactive feedback seeking remains scant. We argue that these links can best be understood from a self-enhancement/self-protection motivational perspective.

Korman (2001) proposed that when the work context clearly communicates performance goals and standards, a self-enhancement motivational system is activated whereby employees perceive greater value in obtaining job-related information as higher levels of work performance bring enhancement of one in the eyes of the self and others. Self-enhancement theory emphasizes the development and maintenance of positive affectivity with regard to the self and says that individuals are actively driven to elevate and maintain positivity of their self-concept by striving for information that helps heighten perceptions of self-worth (Sedikides \& Strube, 1997). In the feed- back context, researchers have recently employed self-enhancement theory to demonstrate that individuals often withdraw from the feedback process out of a desire to maintain levels of self- worth (Anseel \& Lievens, 2006; Woo, Simms, Rupp, \& Gibbons, 2008). Although these results are certainly enlightening, we argue that the self-enhancement motive drives not only reactions to feedback but also the initial impetus to seek feedback.

In an organizational environment that provides consistent, accurate, and easily understandable information with regard to day-to-day employee performance and goal progress, the self-enhancement perspective suggests that individuals will engage in elevated levels of feedbackseeking behavior in order to ensure appropriate task-related behavior and determine normative performance in an effort to increase/maintain levels of self-concept positivity. As such, we expect that perception of feedback quality should positively relate to feedback-seeking behavior. Further, we expect that feedback utility should be an important mediator of this relationship.

Utility, a constituent element of the multidimensional feedback orientation (Linderbaum \& Levy, 2010; London \& Smither, 2002), refers to an individual's tendency to believe that feedback is instrumental in achieving personal effectiveness at work. Utility is thought to be a semimalleable, feedback-related, quasi-dispositional characteristic that evolves in response to contextual influences and remains stable over moderate periods of time (London \& Smither, 2002). Utility 
has been linked to important attitudes (e.g., job involvement) and perceptions (e.g., perceptions of performance appraisal utility and perceived benefits of developmental activities) over and above feedback quality (Linderbuam \& Levy, 2007), suggesting its importance as a predictor of selfregulatory behavior. However, to date empirical work on utility remains limited. We argue that as employees strive for self-enhancement, feedback should come to have more meaning and value for those who work in environments where they are provided high-quality feedback. Further, as individuals become more dispositionally inclined to favor feedback, they should in turn engage in more proactive feedback inquiry.

To date, no research exists that has explicitly examined utility as a mediator of the relationship between feedback quality and feedback seeking; however, some empirical work suggests its influence as an indirect mechanism. For example, Brett and Atwater (2001) found that the perceived usefulness and accuracy of feedback influences the motivation to accept, seek, and use feedback. Furthermore, Makiney and Levy (1998) found that individuals who believed that obtained feedback was useful and credible were more likely to use this feedback when making ratings about an employee. Together these results indicate that trustworthy, useful feedback may be seen as instrumental for the attainment of important outcomes. Based on these findings, as well as the assertion from the self-enhancement perspective suggesting that motivation to obtain information is a function of environmental characteristics that signal opportunities for self-enhancement, the following hypotheses are formulated:

H1a: Perceptions of feedback quality will be positively related to supervisor reports of feedback-seeking frequency.

H1b: The relationship between feedback quality and supervisor reports of feedback seeking will be mediated by perceptions of utility.

\section{THE MAIN AND MODERATING EFFECTS OF GOAL ORIENTATION}

In addition to situational factors, Korman (2001) argued that disposition can independently influence patterns of behavior meant to protect and maintain self-concept positivity. According to this perspective, personality traits are thought to influence the extent to which self-enhancement and self-protection motives predominate, in turn, dictating the self-regulatory strategies employees use to maximize others' perceptions of favorability. Similarly, implicit person theory (Dweck, 1999) indicates that in an organizational context, the "maintenance of self-concept positivity" may take on different meanings for different people and lead employees to behaviorally engage in the feedback process in systematically different ways.

Implicit person theory says that individuals differ in their beliefs about the malleability of personal characteristics such as ability (Dweck, 1999). Those who believe that ability is a fixed attribute and non-amenable to improvement through effort expenditure are classified as entity theorists, whereas individuals who view ability as a quality amenable to change and development are labeled as incremental theorists. Research within an organizational context has demonstrated that implicit person theories influence many aspects of self-regulation including performance on complex decision-making (Tabernero \& Wood, 1999), goal-setting (Wolters, 1998), and adaptive response following task failure (Wood \& Bandura, 1989). Based on one's implicit person theory, individuals embody and act in light of three types of broad goal orientations that influence 
how they approach and interpret feedback-related situations; learning, performance-prove, and performance-avoid goal orientation (Payne, Youngcourt, \& Beaubien, 2007; Siejts, Latham, Tasa, \& Latham, 2004; VandeWalle, 1997). Learning goal orientation is associated with an incremental theory of ability and is characterized by a focus on increased effort, overcoming obstacles, and initiation in order to attain personal growth (Dweck \& Leggett, 1988). In the context of feedback seeking, learning-goal-oriented employees characteristically perceive increased value associated with feedback seeking (Park, Schmidt, Scheu, \& DeShon, 2007; Tuckey et al., 2002; VandeWalle, Ganesan, Challagalla, \& Brown, 2000), and as such behaviorally engage in more feedback seeking out of a desire to clarify performance expectations (Payne et al., 2007; Porath \& Bateman, 2006). Integrating implicit person theory and Korman's (2001) theory of work motivation, it appears that the self-enhancement motivation dominates self-regulation for learning-goal-oriented individuals. Those with a predominant learning goal orientation likely maintain self-concept positivity by pursuing task mastery and securing personal development through incremental gains in knowledge and skill.

Given their inherent drive to master work situations and their willingness to put forth extra effort for the sake of self-development, it is likely that learning-goal-oriented individuals find utility in feedback seeking even in situations where the consistency of feedback quality is questionable. Research suggests that learning-goal-oriented individuals thrive even when presented with "do your best" goals rather than specific goals (Seijts et al., 2004), indicating that these employees are intrinsically inclined to seek out and use feedback to develop competence and maintain self-concept despite an organizational context wherein feedback sources provide quality guidance with little regularity. As such, one would expect elevated perceptions of utility for learning-goal-oriented individuals regardless of ambient feedback quality. Conversely, for those with lower levels of learning goal orientation, decreased perceptions of feedback quality should result in decreased levels of feedback utility. As such, we hypothesize the following:

H2a: Learning goal orientation will be positively related to utility.

$\mathrm{H} 2 \mathrm{~b}$ : The relationship between feedback quality and utility will be moderated by learning goal orientation such that this positive link is weaker for those higher in learning goal orientation than those lower in learning goal orientation.

Those with a performance-prove goal orientation subscribe to an entity theory, viewing ability as a fixed, uncontrollable attribute (Dweck, 1999). Despite seeing little developmental value in feedback (Tuckey et al., 2002), these employees are very outcome focused and regulate behavior (i.e., feedback seeking) according to the potential for positive evaluations (Tuckey et al., 2002). Out of their competitive desire to appear more competent than fellow employees (VandeWalle, 1997), individuals with a high performance-prove goal orientation find a great deal of impression management value in feedback (Park et al., 2007) and as such engage in feedbackseeking behavior (Payne et al., 2007; Porath \& Bateman, 2006).

Thus, like those with a learning goal orientation, individuals with a performance-prove goal orientation are motivated by self-enhancement to maintain elevated levels of self-worth through feedback-seeking behavior. However, for performance-prove-oriented individuals, elevating self-worth involves outperforming others through social comparison and differentiation rather than incremental gains in knowledge and skill (VandeWalle, 1997). The critical distinction between learning-goal-oriented and performance-prove goal-oriented individuals is their view of the feedback encounter; learning-goal-oriented employees see this exchange as 
an opportunity to take away important information regarding appropriate task performance, whereas performance-prove-oriented individuals view the feedback exchange as an occasion to deliver performance information about themselves to important others (Morrison \& Bies, 1991).

Accordingly, for performance-prove goal-oriented individuals, quality of feedback should have little to do with how much value is placed on the act of feedback seeking. For these individuals, feedback - even feedback of low quality — is valued because the feedback exchange is primarily seen as a mechanism by which to direct attention to one's performance and create an important opportunity to manage the impression of others (Morrison \& Bies, 1991; Tuckey et al., 2002), rather than an occasion to obtain feedback for skill development. Thus, one might expect that performance-prove goal-oriented individuals would see value in feedback. However, because feedback carries no appreciable benefit over and above impression management value, these individuals likely find utility in feedback regardless of the quality of day-to-day feedback at their disposal. As such, the positive effects of feedback quality on utility should be attenuated for those with a performance-prove orientation.

H3a: Performance-prove goal orientation will be positively related to perceptions of utility.

$\mathrm{H} 3 \mathrm{~b}$ : The relationship between feedback quality and perceptions of utility will be moderated by performance-prove goal orientation such that this positive link is weaker for those higher in performance-prove goal orientation than it is for those lower in performanceprove goal orientation.

In addition to the self-enhancement motive, Korman's (2001) theory of work motivation (2001) says that employee disposition can activate a second motivational system, self-protective motivation. According to this theory, the motive to self-protect can interfere with task engagement, derail goal-achievement motivation, and lead individuals to engage in "damage control" for ego-defensive reasons. In the feedback-seeking literature, research has shown a clear and consistent link between such forms of self-protection and performance-avoid goal orientation (Park et al., 2007; VandeWalle \& Cummings, 1997).

Those characterized by a performance-avoid goal orientation subscribe to an entity theory, see their ability as fixed and non-amenable to improvement through effort, and focus on their performance (Dweck, 1999). However, this focus is grounded on the avoidance of negative outcomes and evaluations of normative incompetence, orienting these individuals toward the presence of failure-relevant information (Dweck, 1986; VandeWalle, 1997). This focus directs performance-avoid goal-oriented individuals to self-regulate by avoiding situations where they may be subject to other's negative assessments and consequently refrain from direct inquiry (Payne et al., 2007; Porath \& Bateman, 2006). From the self-protection perspective, performanceavoid-oriented individuals are driven to defend self-concept by avoiding situations wherein performance inferiority might be communicated, such as the feedback-seeking exchange. This aversion to self-threatening, failure-relevant information manifests itself in lower perceptions of value and greater costs associated with feedback seeking (VandeWalle, 2003). Because garnering performance information would appear a risky and potentially costly endeavor, it is likely that those with a performance-avoid goal orientation would see little value in feed- back. Moreover, feedback utility would likely remain uninfluenced these individuals, even in a workplace characterized by quality, specific, consistent feedback. As such, we hypothesize the following: 
H4a: Performance-avoid goal orientation will be negatively related to perceptions of utility.

$\mathrm{H} 4 \mathrm{~b}$ : The relationship between feedback quality and perceptions of utility will be moderated by performance-avoid goal orientation such that this positive link is weaker for those higher in performance-avoid goal orientation than it is for those lower in performanceavoid goal orientation.

\section{FEEDBACK SEEKING, ROLE CLARITY, AND JOB PERFORMANCE}

According to Korman (2001), in order to elevate self and other perceptions of worth, individuals will actively strive to obtain information useful for self-growth and effectiveness at work. Indeed, feedback seeking, a key means of obtaining such information, is thought to result in several beneficial performance-related outcomes (Ashford \& Cummings, 1983). To date however, research investigating the relationship between feedback seeking and work effectiveness has led to equivocal findings (i.e., Ang, Cummings, Straub, \& Early, 1993; Ashford \& Black, 1996; Morrison, 1993; Porath \& Bateman, 2006), leading feedback researchers to call for models assessing the indirect mechanisms through which actively sought feedback influences workplace effectiveness (Ashford et al., 2003; London \& Maurer, 2004; Sessa \& London, 2006).

According to feedback theorists, a prominent instrumental outcome of feedback seeking is a reduction in uncertainty with respect to behaviors desired by the organization (Levy, Albright, Cawley, \& Williams, 1995; Morrison, 1993, 2002). Indeed, research suggests that to effectively regulate goal-directed behavior for the sake of successful job performance, one must acquire an accurate understanding of role expectations and performance standards (Renn \& Fedor, 2001; Williams \& Johnson, 2000). However, the research that has explicitly examined role clarity as a mediator of the feedback-seeking/job performance link has met with mixed results (Brown, Ganesan, \& Challagalla, 2001; Whitaker, et al., 2007). Arguably, these indeterminate findings may result from a reliance on retrospective self-reports of feedback seeking and/or job performance. Given that self-reports of behavior differ, perhaps substantially, from behavior observed by others (Podsakoff, MacKenzie, Lee, \& Podsakoff, 2003; Robins \& John, 1997), the current study seeks to reassess the mediating influence of role clarity on the feedbackseeking/job performance link using data from supervisors, the most practical and relevant source for feedback and performance information from the feedback recipient's point of view (Ashford, 1986; Brett, Feldman, \& Weingart, 1990).

Taken together, the bulk of the findings just presented suggest that feedback seeking may bolster an employee's understanding of the expectations of his or her job as well as the comparative level at which he or she is meeting expectations, which in turn influences the success with which an employee carries out his or her job requirements. For these reasons, the present model proposes that feedback seeking should influence task performance through role clarity.

Moreover, enhanced role clarity achieved as a result of feedback-seeking behavior should also increase the frequency of OCBs. Empirical evidence exists suggesting that managers generally define employee performance more broadly to include OCBs (for a review, see Organ, Podsakoff, \& MacKenzie, 2005). Likewise, indirect evidence suggests that employees define their roles to include OCB requirements (Bolino \& Turnley, 2005; Salamon \& Deutsch, 2006), indicating that many behaviors traditionally thought to be discretionary are in fact perceived by employees to be part of their role requirements. If managers routinely include OCB in their definition 
of overall performance, they might be expected to communicate to employees an expectation for collective harmony, leading employees to exhibit role-required OCBs. Indeed, meta-analytic findings that demonstrate a positive relationship between role clarity and OCBs support this relationship (Podsakoff, MacKenzie, \& Bommer, 1996; Podsakoff, MacKenzie, Paine, \& Bachrach, 2000).

Further, the provision of feedback is likely to influence the exhibition of OCBs through the reciprocal social exchange process. Schnake, Cochran, and Dumler (1995) argued that leader behaviors that clarify expectations, work processes, and employee roles are perceived by employees as helping behaviors. Employees feel obligated to reciprocate in kind to such behaviors by supporting the psycho-social context of the workplace. In support of this assertion, supportive leadership behaviors have been empirically linked to OCB (MacKenzie, Podsakoff, \& Rich, 2001; Podsakoff et al., 1996). We argue that the provision of role-clarifying information by supervisors may be viewed by employees as helpful because it reduces uncertainty and indicates concern for the employee's welfare and success, in turn, motivating employees to engage in prosocial behaviors that support the broader workplace context. Based on this rationale, we expect that role clarity that develops as a result of feedback-seeking behavior should facilitate OCBs.

H5a: Role clarity will mediate the effects of supervisor-reported feedback seeking on supervisor-reported task performance.

H5b: Role clarity will mediate the effects of supervisor-reported feedback seeking on supervisor-reported OCBs.

\section{THE MAIN AND MODERATING EFFECTS SOCIAL SKILL}

As evidenced by the contradictory findings of Whitaker et al. (2007) and Brown et al. (2001), feedback seeking may not always lead to clarified role expectations to influence subsequent job performance. Given the inherently social nature of the feedback-seeking exchange process (Ashford \& Tsui, 1991), one's social skill (Hogan \& Shelton, 1998; Witt \& Ferris, 2003) may influence the interpersonal dynamics inherent in the feedback exchange process. Social skill is a social effectiveness construct that taps the extent to which one understands the thoughts and feelings of others, communicates well during interpersonal interactions, perceives useful information as a product of the exchange, and acts appropriately upon that understanding for goal attainment (Hogan \& Shelton, 1998; Witt \& Ferris, 2003). Social skill has received much attention in both the scientific and applied literatures (Ferris, Witt, \& Hochwarter, 2001; Hochwarter, Witt, Treadway, \& Ferris, 2006; Witt \& Ferris, 2003). To date, however, the influence of social skill on the feedback-seeking process has not been examined. Because those with higher social skill should be able to communicate feedback needs more precisely, read others more accurately, extract more precise performance- and role-related information, and integrate more successfully this new information into existing knowledge structures to develop a better sense of role clarity, the following is proposed:

H6a: Social skill will be positively related to role clarity.

H6b: Social skill will moderate the relationship between supervisor-reported feedback seeking and role clarity such that this relationship will be stronger for those with high social skill. 


\section{METHOD}

\section{Participants}

Participants were 293 employed undergraduate students from a large, urban midwestern university who received extra credit and a monetary incentive for their participation in the study. To participate, individuals must have been working at least part time $(20 \mathrm{hr}$ per week) and willing to give permission for the researcher to contact their supervisors. Participants' super- visors were contacted via mail and surveyed regarding the performance of their subordinate. Subordinates whose supervisors did not return surveys were excluded from further analysis. Supervisors returned a total of 202 surveys, yielding a response rate of $68.9 \%$.

The mean age of the subordinate participants was 22.9 years old, with a mean tenure of approximately 22 months $(S D=21.1$ months), working a mean of $24 \mathrm{hr}$ per week $(S D=10.8$ hours). The sample was $71 \%$ female, $89 \%$ Caucasian, and $7.1 \%$ African American; $4.9 \%$ classified them- selves as Asian American, Hispanic American, or Other. Participants held a broad cross-section of occupations, such as accountant, pharmacist assistant, call center manager, administrative assistant, clinical coordinator in a hospital, bank teller, paralegal, licensed practical nurse, customer service representative, and restaurant manager.

The mean age of the supervisors was 39 years, with a mean organizational tenure of approximately 11 years and a mean management tenure of 7 years 2 months. Supervisors had supervised the target employee for a mean of 24 months. The supervisor sample was $56.3 \%$ female; $83 \%$ was Caucasian, 9\% African American, and the remaining 8\% identified themselves as Asian American, Hispanic American, or Other.

\section{Procedure and Design}

Survey packets were distributed in class. Subordinates completed measures designed to assess demographic information, their perceptions of feedback quality, goal orientation, feedback utility, social skill, and their role clarity. Upon survey completion, subordinates completed a consent form allowing their supervisors to be contacted regarding their work performance. The supervisor survey assessed employee task performance and OCBs, subordinate feedback seeking, and the supervisor's demographic information. Supervisors then mailed the completed surveys back to the researchers.

\section{Measures}

Unless otherwise noted, all variables were assessed on a 7-point Likert-type response scale with anchors ranging from 1 (strongly disagree) to 7 (strongly agree).

\section{Subordinate Measures}

Feedback quality. Subordinate perceptions of supervisor and coworker feedback quality were assessed with the Feedback Quality subscale of the Feedback Environment Scale (Steelman et al., 2004). Feedback quality pertains to the perceived informational value of feedback and is defined as the specificity and consistency of feedback that characterizes one's workplace 
(Steelman et al., 2004). This construct was assessed with six items comprising the quality dimension from the abbreviated version of the Feedback Environment Scale $(a=.78)$. A sample item reads, "My supervisor gives me useful feedback about my job performance."

Feedback utility. The Utility subscale of the Feedback Orientation Scale (Linderbaum \& Levy, 2010) was used to tap subordinates' perceptions of feedback utility. The Utility subscale captures individuals' beliefs that feedback can lead to other valued outcomes. A sample item from this five-item scale reads "Feedback contributes to my success at work," and it has demonstrated adequate levels of reliability $(a=.85)$

Goal orientation. Goal orientation was assessed using VandeWalle's (1997) 13-item scale designed for use in the work domain. This scale measures three goal orientation dimensions: learning goal orientation ( 5 items, $a=.89$ ), performance-prove goal orientation ( 4 items, $a=$ .85 ), and performance-avoid goal orientation ( 4 items, $a=.88$ ). A sample item from each scale, respectively includes "I often look for new opportunities to develop new skills and knowledge at work," "I try to figure out what it takes to prove my ability to others at work," and "I prefer to avoid situations at work where I might perform poorly."

Role clarity. We used Sawyer's (1992) 10-item measure of role clarity to assess the extent to which subordinates understood their position $(a=.90)$. This scale measures two facets: clarity of goals and clarity of processes. For example, respondents are asked to indicate how clear they are about the goals and objectives for the job (goal clarity) and how to determine the proper procedures to do the job (process clarity). Responses are rated on a 6-point scale from 1 (very uncertain) to 6 (very certain).

Social skill. Social skill was assessed using Ferris et al.'s seven-item measure ( $a=.87)$. Sample items include, "In social situations, it is always clear to me exactly what to say and do" and "I am keenly aware of how I am perceived by others."

\section{Supervisor Measures}

Feedback seeking. Supervisors were asked to respond to a three-item feedback-seeking scale based on Williams and Johnson's (2000) feedback-seeking measure. This measure $(a=$ .92) was designed to assess the frequency with which subordinates directly seek feedback from supervisors. A sample item reads, "How often does this employee ask you for information about what is required of him/her to function successfully on the job?" This scale is measured with a 6-point scale ranging from 1 (never) to 6 (always).

Performance. A performance measure developed by Williams and Anderson (1991) was used to assess supervisor reported performance. This performance measure has three dimensions: task performance, OCBs directed at the individual (OCBIs), and OCBs directed at the organization (OCBOs). Williams and Anderson reported reliabilities of .91, .88, and .75 respectively. For the purposes of this study, the OBCI and OCBO subscales were combined into an overall OCB measure. "Adequately completes assigned duties" is a sample item measuring task performance

$(a=.82)$, "Helps others who have a heavy work load" is a sample OCB item $(a=.89)$. 


\section{RESULTS}

Means, standard deviations, internal reliabilities, and inter-correlations among the variables are reported in Table 1. All measures showed adequate internal reliabilities, with coefficient alphas ranging from .78 to .92 . The bivariate correlations were largely consistent with the hypothesized relationships. Feedback quality was significantly associated with feedbackseeking frequency

$(r=.22, p<.01)$, learning goal orientation was positively related to feedback utility $(r=.52$, $p<.01$ ), and performance-avoid goal orientation had a significant negative association with utility $(r=-.35, p<.01)$.

Following best practices for tests of mediation (MacKinnon, Lockwood, \& Williams, 2004; Preacher \& Hayes, 2005, Shrout \& Bolger, 2002), we tested indirect effects using Preacher and Hayes's (2004) SPSS macro that incorporates the Sobel test and bootstrapped confidence intervals in the estimation of indirect effects. Supporting H1a, feedback quality was positively related to feedback seeking, as indicated by the significant unstandardized regression coefficient $(B=$

$.32, t=4.57, p<.01$; Table 2 ). Furthermore, utility was found to meditate the positive relationship between feedback quality and supervisor ratings of feedback seeking (.15), supporting H1b. The Sobel two-tailed test of significance, which assumes a normal distribution, demonstrated that the mediating effect was significant $(z=3.75, p<.01)$. Moreover, the bootstrap results corroborated the Sobel test as the bootstrapped 95\% confidence interval around the indirect effect did not contain zero $(.07, .25$; Table 2$)$.

Table 3 reports the standardized regression results for testing $\mathrm{H} 2 \mathrm{a}$ to $\mathrm{H} 4 \mathrm{~b}$. Prior to the analysis, all variables were mean-centered (Aiken \& West, 1991). As shown, controlling for the other forms of goal orientation, learning goal orientation was a significant predictor of utility $(\beta$ $=.33$,

$p<.01$ ), supporting H2a. Moreover, the Feedback Quality $\times$ Learning Goal Orientation interaction term added significant incremental variance at Step $3\left(!^{\prime} 1 R^{2}=.02, p<.05\right)$. Using procedures outlined by Aiken and West (1991), the observed interaction was plotted to examine the form of

the moderated relationship. Figure 2 illustrates that, as expected, there was a weaker positive

TABLE 1

Means, Standard Deviations, Correlations, and Reliabilities of all Variables

\begin{tabular}{lcccccccccc}
\hline & 1 & 2 & 3 & 4 & 5 & 6 & 7 & 8 & 9 & 10 \\
\hline 1. Feedback quality & .78 & & & & & & & & \\
2. Learning goal orientation & $.25^{* *}$ & .89 & & & & & & & \\
3. Perf-Prove goal orientation & .11 & .11 & .85 & & & & & & \\
4. Perf-Avoid goal orientation & $-.20^{* *}$ & $-.44^{* *}$ & $.23^{* *}$ & .88 & & & & & \\
5. Feedback utility & $.43^{* *}$ & $.52^{* *}$ & .11 & $-.35^{* *}$ & .85 & & & & & \\
6. Feedback seeking & $.22^{* *}$ & $.22^{* *}$ & .06 & $-.25^{* *}$ & $.31^{* *}$ & .92 & & & & \\
7. Role clarity & $.15^{*}$ & $.24^{* *}$ & $.15^{*}$ & $-.22^{* *}$ & .12 & $.18^{* *}$ & .90 & & \\
8. Social skill & $.31^{* *}$ & $.31^{* *}$ & $.20^{* *}$ & $-.25^{* *}$ & $.27^{* *}$ & $.30^{* *}$ & $.45^{* *}$ & .87 & \\
9. Task performance & $.15^{*}$ & .12 & .05 & $-.14^{*}$ & .06 & $.46^{* *}$ & $.34^{* *}$ & .03 & .82 \\
10. OCB & .09 & $.16^{*}$ & .10 & -.01 & .08 & $.21^{* *}$ & $.31^{* *}$ & .12 & $.64^{* *}$ & .89 \\
$M$ & 4.20 & 4.40 & 3.64 & 2.21 & 4.15 & 2.69 & 4.27 & 4.28 & 4.41 & 3.85 \\
SD & .92 & .69 & .99 & .99 & .78 & .97 & .82 & .70 & .50 & .54 \\
\hline
\end{tabular}

Note. Perf-Prove Goal Orientation = Performance-Prove Goal Orientation; Perf-Avoid Goal Orientation = Performance-Avoid Goal Orientation; OCB = Organizational Citizenship Behavior.

${ }^{*} p<.05 .{ }^{*} p<.01$. 
Table 2

Results of Mediation Analyses for Feedback Utility on Feedback-Seeking Behavior

\begin{tabular}{|c|c|c|c|c|c|c|c|c|}
\hline \multicolumn{5}{|l|}{ Variables } & $b$ & $S E$ & $t$ & $p$ \\
\hline \multirow{4}{*}{\multicolumn{5}{|c|}{$\begin{array}{l}\text { Feedback seeking regressed on feedback quality } \\
\text { Feedback utility regressed on feedback quality } \\
\text { Feedback seeking regressed on feedback utility, controlling for feedback quality } \\
\text { Feedback seeking regressed on feedback quality, controlling for feedback utility }\end{array}$}} & .32 & .07 & 4.57 & .01 \\
\hline & & & & & .38 & .05 & 7.60 & .01 \\
\hline & & & & & .38 & .09 & 4.22 & .01 \\
\hline & & & & & .17 & .07 & 2.42 & .04 \\
\hline & Value & $S E$ & $L L 95 \% C I$ & $U L 95 \% C I$ & $z$ & $p$ & & \\
\hline \multirow[t]{2}{*}{ Indirect effect using normal distribution (Sobel) } & .15 & .04 & .07 & .23 & 3.75 & .01 & & \\
\hline & $M$ & $S E$ & LL 95\% CI & $U L 95 \% C I$ & & & & \\
\hline Bootstrap results for indirect effect & .15 & .04 & .07 & .25 & & & & \\
\hline
\end{tabular}

Note. Unstandardized regression coefficients reported. Bootstrap sample size 5,000. LL = lower limit; CI = confidence interval; UL $=$ upper limit.

TABLE 3

Main Effect and Hierarchical Moderated Multiple Regression Results for Goal Orientation

\begin{tabular}{|c|c|c|c|}
\hline & \multirow[b]{2}{*}{$R^{2}$} & \multicolumn{2}{|c|}{ Feedback Utility } \\
\hline & & $\Delta R^{2}$ & $\beta$ \\
\hline \multicolumn{4}{|l|}{ Regression Step } \\
\hline 1. Perf-Prove goal orientation & .15 & & .06 \\
\hline Perf-Avoid goal orientation & & & $-.16^{*}$ \\
\hline 2. Feedback quality & .37 & .22 & $.29 * *$ \\
\hline Learning goal orientation & & & $.33^{* *}$ \\
\hline 3. Feedback Quality $\times$ Learning Goal Orientation & .39 & .02 & $-.17^{*}$ \\
\hline 1. Learning goal orientation & .28 & & $.38 * *$ \\
\hline Perf-Avoid goal orientation & & & $-.15^{*}$ \\
\hline 2. Feedback quality & .37 & .09 & $.30 * *$ \\
\hline Perf-Prove goal orientation & & & .06 \\
\hline 3. Feedback Quality $\times$ Perf-Prove Goal Orientation & .37 & .00 & -.03 \\
\hline 1. Learning goal orientation & .27 & & $.37 * *$ \\
\hline Perf-Prove goal orientation & & & .06 \\
\hline 2. Feedback quality & .36 & .09 & $.32 * *$ \\
\hline Perf-Avoid goal orientation & & & $-.16^{*}$ \\
\hline 3. Feedback Quality $\times$ Perf-Avoid Goal Orientation & .38 & .02 & $-.15^{*}$ \\
\hline
\end{tabular}

Note. Perf-Prove Goal Orientation = Performance-Prove Goal Orientation; Perf-Avoid Goal Orientation $=$ Performance-Avoid Goal Orientation.

${ }^{*} p<.05 .{ }^{*}{ }^{*} p<.01$.

slope describing the relationship between perceptions of feedback quality and feedback utility for those with higher levels of learning goal orientation. The slope of the regression line for these individuals was not significantly different from zero, $t(3,202)=.85, n s$. Conversely, simple slopes were significantly different from zero for those with lower levels of learning 


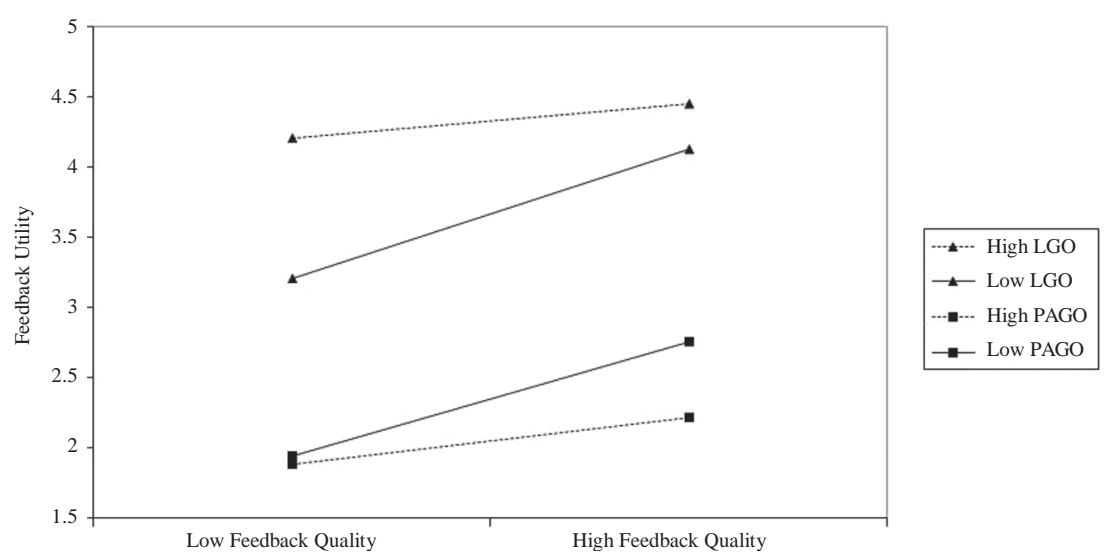

FIGURE 2 The interactions of feedback quality and goal orientation on feedback utility.

Note. $\mathrm{LGO}=$ learning goal orientation; PAGO = performance-avoid goal orientation.

goal orientation, $t(3,202)=3.01, p<.01$. These results provide support for H2b. In contrast, performance-prove goal orientation was found to be unrelated to perceptions of utility $(\beta=.06$, $n s)$. Furthermore, the Feedback Quality $\times$ Performance-Prove Orientation interaction failed to attain statistical significance $(\beta=-.03, n s)$. As such, $\mathrm{H} 3 \mathrm{a}$ and $\mathrm{H} 3 \mathrm{~b}$ were not supported. Last, as hypothesized, performance-avoid goal orientation was negatively associated with utility $(\beta=$ $-.16, p<.01)$, supporting H4a. In addition, the Feedback Quality $\times$ Performance-Prove Goal Orientation interaction term accounted for significant incremental variance at Step $3\left(!^{\prime} 1 R^{2}=.02\right.$, $p<.05$ ). As shown in Figure 2, the positive link between feedback quality and feedback utility is weaker for those with higher levels of performance-avoid goal orientation. The slope of the regression line was not significantly different from zero, $t(3,201)=1.09, n s$. However, for those with lower levels of performance-avoid goal orientation, the simple slope was significantly different from zero, $t(3,201)=3.85, p<.01$.

The results for the tests of $\mathrm{H} 5 \mathrm{a}$ and $\mathrm{H} 5 \mathrm{~b}$ are reported in Table 4. As shown, role clarity was found to mediate the positive relationship between feedback seeking and task performance (.43), supporting H5a. The Sobel test indicated that the indirect effect was significant $(z=5.38, p<$ $.01)$, and the bootstrapped $95 \%$ confidence interval around the indirect effect did not contain zero $(.31, .58)$. Similarly, we found support for H5b. Role clarity was a significant mediator of the feedback seeking-OCB link (.10) and bootstrap results did not contain zero $(.03, .19)$.

Social skill was a significant predictor of role clarity $(\beta=.51, p<.01)$, supporting H6a. However, the Feedback Seeking $\times$ Social Skill Interaction term failed to account for a significant amount of variance over and above that of the main effects $\left(!^{\prime} 1 R^{2}=.00, n s\right)$. As such, H6b was not supported.

To simultaneously examine the hypothesized relationships found to be significant in the previous analyses, we tested the path model presented in Figure 1 relating all variables under examination. Mplus v 4.21 (Muthén \& Muthén, 2007) was used to fit this model to the covariance matrix, which resulted in acceptable fit as evidenced by fit indices, $\chi^{2}(27)=$ 33.76 ,

$p<.05$; comparative fit index $=.96$, non-normed fit index $=.95$, root mean square error of approximation $=.06$. Inspection of $t$ values revealed that all paths were significant, and the largest 


\section{TABLE 4}

Results of Mediation Analyses for Role Clarity on OCBs and Task Performance

\begin{tabular}{|c|c|c|c|c|c|c|c|c|}
\hline \multicolumn{5}{|l|}{ Variables } & $b$ & $S E$ & $t$ & $p$ \\
\hline \multicolumn{5}{|l|}{ Task Performance regressed on feedback seeking } & .49 & .07 & 7.36 & .01 \\
\hline \multicolumn{5}{|l|}{ Role Clarity regressed on feedback seeking } & .21 & .05 & 4.20 & .01 \\
\hline \multicolumn{5}{|c|}{ Task Performance regressed on role clarity, controlling for feedback seeking } & .20 & .04 & 4.97 & .01 \\
\hline \multicolumn{5}{|c|}{ Task Performance regressed on feedback seeking, controlling for role clarity } & .19 & .05 & 3.80 & .01 \\
\hline \multicolumn{5}{|l|}{ OCB regressed on feedback seeking } & .20 & .04 & 4.92 & .01 \\
\hline \multicolumn{5}{|c|}{ Role Clarity regressed on feedback seeking } & .21 & .05 & 4.15 & .01 \\
\hline \multicolumn{5}{|c|}{ OCB regressed on role clarity, controlling for feedback seeking } & .34 & .05 & 6.78 & .01 \\
\hline \multicolumn{5}{|c|}{ OCB regressed on feedback seeking, controlling for role clarity } & .14 & .05 & 2.34 & .03 \\
\hline & Value & $S E$ & $L L 95 \%$ CI & $U L 95 \% C I$ & $z$ & $p$ & & \\
\hline \multicolumn{9}{|l|}{ Indirect effect using normal distribution (Sobel) } \\
\hline Mediation of role clarity on task performance & .43 & .08 & .28 & .59 & 5.38 & .01 & & \\
\hline \multirow[t]{2}{*}{ Mediation of role clarity on $\mathrm{OCB}$} & .10 & .04 & .02 & .17 & 2.39 & .05 & & \\
\hline & $M$ & $S E$ & $L L 95 \%$ CI & $U L 95 \% C I$ & & & & \\
\hline \multicolumn{9}{|l|}{ Bootstrap results for indirect effect } \\
\hline Mediation of role clarity on task performance & .44 & .07 & .31 & .58 & & & & \\
\hline Mediation of role clarity on OCB & .11 & .04 & .03 & .19 & & & & \\
\hline
\end{tabular}

Note. Unstandardized regression coefficients reported. Bootstrap sample size 5,000. LL = lower limit; CI $=$ confidence interval; $\mathrm{UL}=$ upper limit.

modification index value was 2.21 , indicating that no additional path would provide a nontrivial increment in model fit. Standardized paths are presented in Figure 1.

\section{DISCUSSION}

The hypotheses for this study were largely supported. In accordance with our theoretical framework and consistent with feedback process models (Gregory et al., 2008; London \& Maurer, 2004), our results indicate that feedback sources who supply high-quality, specific feedback may help craft contexts that stimulate self-enhancement by influencing the emergence of feedback utility. Perceptions of feedback utility in turn positively influence the frequency of feedback seeking from others in the workplace, employees' perceptions of role clarity, and ultimately their task performance and OCBs.

Our results have several practical implications. Whereas very little research has been conducted with an eye toward training organizational actors to provide better feedback, the results presented in this study suggest that an individual's feedback utility may be influenced by interventions initiated to alter the quality of feedback provided to employees. For example, feedback scholars advocate that utility might be developed through training efforts that focus on proper feedback provision and the clear communication of performance standards as well as the explicit linking of employee performance to financial or operational indices (e.g., London \& Smither, 2002). 
The importance of feedback quality for evoking utility becomes increasingly salient as jobs become more complex and employees are required to operate autonomously (London \& Maurer, 2004). For example, employees are increasingly asked to work independently (e.g., telecommuters), far away from their home organization (e.g., expatriates), or within an increasingly diverse and multicultural workforce (Rau \& Hyland, 2002; van Knippenberg, De Dreu, \& Homan, 2004). As a result, employees are likely finding it increasingly difficult to gauge how others view their performance and obtain feedback unless they seek that feedback directly. As the need for self-directed, continuous learning becomes more important, managers have to question what can be done to better suit employees for work situations where role and process information must be actively elicited. In general, the results of this study suggest that employees are more motivated to seek out and use feedback if they know that the feedback provided will be highly informative and provide specific information for effective performance and enhancement/maintenance of self-concept.

Given the significant link between feedback quality and utility, there is clear appeal in the development of feedback-delivery training that fosters the emergence of utility as perceived by employees. However, the results of this study suggest that such efforts may not be equally beneficial to all employees. Whereas our results suggest that feedback of low quality may actively dampen feedback utility for most employees (those with a high learning goal orientation notwithstanding), in this study utility remained unaffected for performance-avoid orientated individuals even when high-quality feedback was available in the organizational milieu.

Our results mirror the generally adaptive and maladaptive influences of incremental and entity theories, respectively, on feedback-related processes that have led researchers to suggest that employees be selected based on goal orientation (Fortunato \& Goldblatt, 2006; VandeWalle, Brown, Cron, \& Slocum, 1999). Fortunately, with respect to highly avoidant employees, effective interventions have been developed that have proven to be useful for minimizing the negative effects of performance-avoid orientation in the workplace. For example, training programs based on self-persuasion techniques have been found to be very beneficial in altering individuals' implicit beliefs about abilities and skills (e.g., Heslin, Latham, \& VandeWalle, 2005; Heslin, VandeWalle, \& Latham, 2006). These results, in combination with the results of the present study, suggest that feedback utility training and selfpersuasion techniques might be usefully applied in tandem to help facilitate among existing employees the emergence of an incrementalist mindset while minimizing the influence of the fixed, entity perspective that characterizes performance-avoid goal orientation.

Last, the results of this study indicate that role clarity partially mediated the influence of feedback seeking on evaluations of task performance and OCBs. Our findings are particularly robust given that both feedback-seeking and performance data were gathered from supervisors, minimizing biases associated with self-reported behavioral information (Podsakoff, et al., 2003; Robins \& John, 1997). The mediation of role clarity clearly emphasizes the importance of providing a well-known referent standard of performance to employees, facilitating improvement in task performance. Our findings also have important implications for the relationship between feedback seeking, role clarity, and OCBs. Specifically, our results imply that (a) feedback-seeking behavior provides employees with an enhanced understanding of the types of OCBs that are valued by the organization, and (b) role clarity attained as a consequence of feedback seeking from supervisors evokes a sense of obligation on the part of employees to reciprocate back to the organization in the form of OCBs. These results suggest that training feedback sources to provide feedback high 
in quality may effectively curb misdirected or insufficient effort on the part of those lacking a clear understanding of role expectations.

\section{Limitations and Future Directions}

Although our findings have helped to answer several calls in the feedback-seeking literature, our study did have several limitations. For example, this study relied on employed undergraduate students with modest job tenure. The mean tenure for subordinates was just under 2 years; as such, generalizability of these results may be somewhat bounded. If long-term experience with high-quality feedback is more likely to influence feedback utility than short-term experience, data gathered on a sample with relatively little tenure may produce inaccurate estimates of the relationship between feedback quality and feedback utility. As such, it is important that future studies employ samples that better represent employees with more tenure and/or employ tenure as an important moderator of this relationship. In a related vein, our sample was overwhelmingly Caucasian (89\%) and female (71\%). To the extent that these demographic characteristics influence volitional feedback inquiry (Fletcher, 1999; Wanberg \& Kammeyer-Mueller, 2000), use of this sample may have restricted the range on these relevant variables. Furthermore, hypothesis testing was conducted in a cross-sectional manner, which limits the extent that causality can be assessed. Longitudinal research examining how feedback quality and personality characteristics influence perceptions of employee feedback utility is another area for additional research. Last, empirical research assessing individuals' perceptions of feedback quality as they change jobs, supervisors, or companies and their attendant effects on feedback utility may be insightful for understanding how individuals' perceptions of feedback utility can develop and change over time and situations.

Contrary to expectations, we found no main effect for performance-prove goal orientation on feedback quality, nor did it interact with feedback quality to influence feedback utility. This unexpected finding may make sense in light of research conducted by achievement motivation researchers who note that learning and performance-prove goal orientation both facilitate task concentration and intrinsic motivation, but they may not always elicit the same motivational processes or lead to identical outcomes (Elliot \& Church, 1997). It may be that in an environment wherein performance feedback is characteristically of low quality, the normative evaluations that motivate those with a performance-prove goal orientation may appear nondifferentiating, non- specific, or otherwise not useful for demonstrating one's competence relative to that of others, ultimately disrupting affective investment in comparative evaluation for these individuals. In such situations, performance-prove goal-oriented individuals may feel discouraged from the active solicitation of such information, lowering perceptions of feedback utility. Future research should seek to clarify these issues and identify contextual elements that do interact with performance- prove goal orientation to influence how prove-oriented individuals respond and react to feedback situations.

In addition, future research should investigate the differential effects of feedback-seeking source on the links between utility, feedback seeking, and role clarity. Extant feedbackseeking research indicates that employees consider both supervisors and coworkers when basing perceptions of contextual influences on feedback-seeking behavior (Morrison \& Vancouver, 2000; Whitaker et al., 2007). Arguably, employees who receive higher quality feedback from peers than supervisors should perceive more utility in the feedback from coworkers and 
subsequently seek less feedback from the supervisor than peers. As such, future research empirically assessing theoretical models of how individuals engage in the feedback-seeking process (e.g., Gregory et al., 2008; London \& Maurer, 2004; Morrison, 2002) should carefully consider the distinct influence of feedback source on feedback inquiry.

Last, we found no support for social skill as a moderator of the feedback-seeking/role clarity link. However, as it is likely that some dispositional variables are beneficial for the sake of obtaining accurate performance information, future research should identify and examine employee characteristics that either augment or attenuate the relationship between feedback seeking and role clarity.

\section{Conclusion}

Our findings emphasize the importance of feedback quality in organizations that seek to increase feedback-seeking behaviors and improve job performance. We have demonstrated that the presence of high-quality feedback influences perceptions of employee feedback utility; however, we also show that this relationship is moderated by goal orientation. We have also demonstrated that feedback seeking is related to both task behavior and OCBs through the partial mediating effects of role clarity. Overall, this model provides new directions for research on feedback quality and generates useful implications for both researchers and practitioners seeking to increase important individual and organizational outcomes.

\section{ACKNOWLEDGMENTS}

We thank the editor and two anonymous reviewers for their valuable and constructive comments on this manuscript.

\section{REFERENCES}

Aiken, L. S., \& West, S. G. (1991). Multiple regression: Testing and interpreting interactions. Thousand Oaks, CA: Sage Publications, Inc.

Ang, S., Cummings, L., Straub, D., \& Early, P. (1993). The effects of information technology and the perceived mood of the feedback giver on feedback seeking. Information Systems Research, 4, 240-261.

Anseel, F., \& Lievens, F. (2006). Certainty as a moderator of feedback reactions: A test of the strength of the selfverification motive. Journal of Occupational and Organizational Psychology, 79, 533-551

Ashford, S. (1986). Feedback-seeking in individual adaptation: A resource perspective. Academy of Management Journal, $29,465-487$.

Ashford, S., \& Black, J. (1996). Proactivity during organizational entry: The role of desire for control. Journal of Applied Psychology, 81, 199-214.

Ashford, S., Blatt, R., \& VandeWalle, D. (2003). Reflections on the looking glass: A review of research on feedbackseeking behavior in organizations. Journal of Management, 29, 773-799.

Ashford, S., \& Cummings, L. (1983). Feedback as an individual resource: Personal strategies of creating information. Organizational Behavior and Human Performance, 32, 370-398.

Ashford, S. J., \& Tsui, A. S. (1991). Self-regulation for managerial effectiveness: The role of active feedback-seeking. Academy of Management Journal, 34, 251-280.

Bolino, M., \& Turnley, W. (2005). The personal costs of citizenship behavior: The relationship between individual initiative and role overload, job stress, and work-family conflict. Journal of Applied Psychology, 90, 740-748. 
Brett, J. F., \& Atwater, L. E. (2001). 360-degree feedback: Accuracy, reactions, and perceptions of usefulness. Journal of Applied Psychology, 86, 930-942.

Brett, J. M., Feldman, D., \& Weingart, L. R. (1990). Feedback-seeking behavior of new hires and job changers. Journal of Management, 16, 737-749.

Brown, S. P., Ganesan, S., \& Challagalla, G. (2001). Self-efficacy as a moderator of information-seeking effectiveness. Journal of Applied Psychology, 86, 1043-1051.

Chen, Z., Lam, W., \& Zhong, J. A. (2007). Leader-member exchange and member performance: A new look at individuallevel negative feedback-seeking behavior and team-level empowerment climate. Journal of Applied Psychology, 92(1), 202-212.

Dweck, C. S. (1986). Motivational processes affecting learning. American Psychologist, 41, 1040-1048.

Dweck, C. S. (1999). Self-theories: Their role in motivation, personality, and development. Philadelphia: The Psychology Press.

Dweck, C. S., \& Leggett, E. L. (1988). A social-cognitive approach to motivation and personality. Psychological Review, 95, 256-273.

Elliot, A. J., \& Church, M. A. (1997). A hierarchical model of approach and avoidance achievement motivation. Journal of Personality and Social Psychology, 72, 218-232

Ferris, G. R., Witt, L. A., \& Hochwarter, W. A. (2001). Interaction of social skill and general mental ability on job performance and salary. Journal of Applied Psychology, 86, 1075-1082.

Fletcher, C. (1999). The implications of research on gender differences in self-assessment and 360-degree appraisal. Human Resource Management Journal, 9(1), 39-46.

Fortunato, V., \& Goldblatt, A. (2006). An examination of goal orientation profiles using cluster analysis and their relationship with dispositional characteristics and motivational response patterns. Journal of Applied Psychology, 36, 2150-2183.

Gregory, J. B., Levy, P. E., \& Jeffers, M. (2008). Development of a model of the feedback process within executive coaching. Consulting Psychology Journal: Practice and Research, 60, $42-56$.

Heslin, P. A., Latham, G. P., \& VandeWalle, D. (2005). The effect of implicit person theory on performance appraisals. Journal of Applied Psychology, 90, 842-856.

Heslin, P. A., VandeWalle, D., \& Latham, G. P. (2006). Keen to help? Managers' IPTs and their subsequent employee coaching. Personnel Psychology, 59, 871-902.

Hochwarter, W. A., Witt, L. A., Treadway, D. C., \& Ferris, G. A. (2006). Interaction of organizational support and social skill on job performance. Journal of Applied Psychology, 91, 482-489.

Hogan, R., \& Shelton, D. (1998). A socioanalytic perspective on job performance. Human Performance, 11, $129-144$.

Kanfer, R., \& Ackerman, P. L. (1989). Motivation and cognitive abilities: An integrative/aptitude-treatment interaction approach to skill acquisition. Journal of Applied Psychology, 74, 657-690.

Kluger, A., \& DeNisi, A. (1996). Effects of feedback intervention on performance: A historical review, a meta-analysis, and a preliminary feedback intervention theory. Psychological Bulletin, 119, 254-284.

Korman, A. K. (2001). Self-enhancement and self-protection: Towards a theory of motivation. In M. Erez, U. Kleinbeck, \& H. Thierry (Eds.), Work motivation in the context of globalizing economy (pp. 121-130). Mahwah, NJ: Erlbaum.

Lam, W., Huang, X., \& Snape, E. (2007). Feedback seeking behavior and leader Member exchange: Do supervisor attributions matter? Academy of Management Journal, 50, 348-363.

Levy, P., Albright, M., Cawley, B., \& Williams, J. (1995). Situational and individual determinants of feedback seeking: A closer look at the process. Organizational Behavior \& Human Decision Processes, 62, 23-34.

Linderbaum, B. G., \& Levy, P. E. (2007). The development and validation of the Feedback Orientation Scale. Paper presented at the 22nd Annual Meeting of the Society for Industrial and Organizational Psychology, New York, NY.

Linderbaum, B. G., \& Levy, P. E. (2010, April). The development and validation of the Feedback Orientation Scale (FOS). Journal of Management, 36, 1372-1405.

London, M. (2003). Job feedback: Giving, seeking and using feedback for performance improvement (2nd ed.). Mahwah, NJ: Erlbaum.

London, M., \& Maurer, T. J. (2004). Leadership development: A diagnostic model for continuous learning in dynamic organizations. In J. Antonakis, A. T. Cianciolo, \& R. J. Sternberg (Eds.), The nature of leadership (pp. 222-246). Thousand Oaks, CA: Sage.

London, M., \& Smither, J. M. (2002). Feedback orientation, feedback culture, and the longitudinal performance management process. Human Resource Management Review, 12, 81-100. 
MacKenzie, S. B., Podsakoff, P. M., \& Rich, G. A. (2001). Transformational and transactional leadership and salesperson performance. Academy of Marketing Science Journal, 29, 115-134.

MacKinnon, D. P., Lockwood, C. M., \& Williams, J. (2004). Confidence limits for the indirect effect: Distribution of the product and resampling methods. Multivariate Behavioral Research, 39, 99-128.

Makiney, J. D., \& Levy, P. E. (1998). The influence of self ratings versus peer ratings on supervisors' performance judgments. Organizational Behavior and Human Decision Processes, 74, 212-228.

Morrison, E. (1993). Longitudinal study of the effects of information seeking on newcomer socialization. Journal of Applied Psychology, 78, 173-183.

Morrison, E. (2002). Newcomers' relationships: The role of social network ties during socialization. Academy of Management Journal, 45, 1149-1160.

Morrison, E., \& Bies, R. (1991). Impression management in the feedback-seeking process: A literature review and research agenda. Academy of Management Review, 16, 522-541.

Morrison, E. W., \& Vancouver, J. B. (2000). Within-person analysis of information seeking: The effects of perceived costs and benefits. Journal of Management, 26, 119-137.

Muthén, L. K., \& Muthén, B. O. (2007). Mplus user's guide (Version 4.21). Los Angeles, CA: Muthén \& Muthén.

Organ, D. W., Podsakoff, P. M., \& MacKenzie, S. B. (2005). Organizational citizenship behavior: Its nature, antecedents, and consequences. Thousand Oaks, CA: Sage.

Park, G., Schmidt, A. M., Scheu, C. R., \& DeShon, R. P. (2007). A process model of goal orientation and feedback seeking. Human Performance, 20, 119-145.

Payne, S. C., Youngcourt, S. S., \& Beaubien, J. M. (2007). A meta-analytic examination of the goal orientation nomological net. Journal of Applied Psychology, 92, 128-150.

Podsakoff, P. M., MacKenzie, S. B., \& Bommer, W. H. (1996). Transformational leader behaviors and substitutes for leadership as determinants of employee satisfaction, commitment, trust and organizational citizenship behaviors. Journal of Management, 22, 185-211.

Podsakoff, P. M., MacKenzie, S. B., Lee, J. Y., \& Podsakoff, N. P. (2003). Common method biases in behavioral research: A critical review of the literature and recommended remedies. Journal of Applied Psychology, 88, 879-903.

Podsakoff, P., MacKenzie, S., Paine, J., \& Bachrach, D. (2000). Organizational citizenship behaviors: A critical review of the theoretical and empirical literature and suggestions for future research. Journal of Management, 26, 513-563.

Porath, C. L, \& Bateman, T. (2006). Self-regulation: From goal orientation to job performance. Journal of Applied Psychology, 91, 185-192.

Preacher, K. J., \& Hayes, A. F. (2004). SPSS and SAS procedures for estimating indirect effects in simple mediation models. Behavior Research Methods, Instruments, \& Computers, 36, 717-731.

Preacher, K. J., \& Hayes, A. F. (2005). SPSS and SAS procedures for estimating indirect effects in multiple mediator models. Retrieved from http://www.comm.ohio-state.edu/ahayes/SPSS\%20programs/indirect.htm.

Rau, B., \& Hyland, M. (2002). Role conflict and flexible work arrangements: The effects on applicant attraction. Personnel Psychology, 55, 111-136.

Renn, R. W., \& Fedor, D. B. (2001). Development and field test of a feedback seeking, self-efficacy, and goal setting model of work performance. Journal of Management, 27, 563-583.

Robins, R. W., \& John, O. P. (1997). The quest for self-insight: Theory and research on accuracy and bias in selfperception. In R. Hogan, J. Johnson, \& S. Briggs (Eds.), Handbook of personality psychology (pp. 649-679). New York: Academic Press.

Salamon, S., \& Deutsch, Y. (2006). OCB as a handicap: An evolutionary psychological perspective. Journal of Organizational Behavior, 27, 185-199.

Sawyer, J. (1992). Goal and process clarity: Specification of multiple constructs of role ambiguity and a structural equation model of their antecedents and consequences. Journal of Applied Psychology, 77, 130-142.

Schnake, M., Cochran, D. S., \& Dumler, M. P. (1995). Encouraging organizational citizenship: The effects of job satisfaction, perceived equity, and leadership. Journal of Managerial Issues, 2, 209-221.

Sedikides, C., \& Strube, M. J. (1997). Self-evaluation: To thine own self be good, to thine own self be sure, to thine own self be true, and to thine own self be better. In M. P. Zanna (Ed.), Advances in experimental social psychology (pp. 209-269). New York: Academic Press.

Seijts, G. H., Latham, G. P., Tasa, K., \& Latham, B. W. (2004). Goal setting and goal orientation: An integration of two different yet related literatures. Academy of Management Journal, 47, 227-239.

Sessa, V. I., \& London, M. (2006). Continuous learning in organizations. Mahwah, NJ: Erlbaum. 
Shrout, P. E., \& Bolger, N. (2002). Mediation in experimental and nonexperimental studies: New procedures and recommendations. Psychological Methods, 7, 422-445.

Steelman, L., Levy, P., \& Snell, A.F. (2004). The Feedback Environment Scale (FES): Construct definition, measurement, and validation. Education and Psychological Measurement, 64, 165-184.

Tabernero, C., \& Wood, R. E. (1999). Implicit theories versus the social construal of ability in self-regulation and performance on a complex task. Organizational Behavior and Human Decision Processes, 78, 104-127.

Taylor, M., Fisher, C., \& Ilgen, D. (1984). Individuals' reactions to performance feedback in organizations: A control theory perspective. In K. Rowland \& J. Ferris (Eds.), Research in Personnel and Human Resource Management (Vol. 2, pp. 91-124). Greenwich, CT: JAI.

Tuckey, M., Brewer, N., \& Williamson, P. (2002). The influence of motives and goal orientation on feedback seeking. Journal of Occupational \& Organizational Psychology, 75, 195-216.

VandeWalle, D. (1997). Development and validation of a work domain goal orientation instrument. Educational and Psychological Measurement, 57, 995-1015.

VandeWalle, D. (2003). A goal orientation model of feedback-seeking behavior. Human Resource Management Review, $13,581-604$.

VandeWalle, D., Brown, S. P., Cron, W. L., \& Slocum, J. W., Jr. (1999). The influence of goal orientation and selfregulation tactics on sales performance: A longitudinal field test. Journal of Applied Psychology, 84, 249-259.

VandeWalle, D., \& Cummings, L. (1997). A test of the influence of goal orientation on the feedback seeking process. Journal of Applied Psychology, 82, 390-400.

VandeWalle, D., Ganesan, S., Challagalla, G., \& Brown, S. (2000). An integrated model of feedback-seeking behavior: Disposition, context, and cognition. Journal of Applied Psychology, 85, 996-1003.

van Knippenberg, D., De Dreu, C. K. W., \& Homan, A. C. (2004). Work group diversity and group performance: An integrative model and research agenda. Journal of Applied Psychology, 98, 1008-1022.

Wanberg, C., \& Kammeyer-Mueller, J. (2000). Predictors and outcomes of proactivity in the socialization process. Journal of Applied Psychology, 85, 373-385.

Whitaker, B., Dahling, J., \& Levy, P. (2007). The development of a feedback environment-role clarity model of work performance. Journal of Management, 33, 570-591.

Williams, L., \& Anderson, S. (1991). Job satisfaction and organizational commitment as predictors of organizational citizenship and in-role behaviors. Journal of Management, 17, 601-617.

Williams, J., \& Johnson, M. (2000). Self-supervisor agreement: The influence of feedback seeking on the relationship between self and supervisor ratings of performance. Journal of Applied Social Psychology, 30, 275-292.

Witt, L. A., \& Ferris, G. R. (2003). Social skill as moderator of the conscientiousness-performance relationship: Convergent results across four studies. Journal of Applied Psychology, 88, 809-820.

Wolters, C. (1998). Self-regulated learning and college students' regulation of motivation. Journal of Educational Psychology, 90, 224-235.

Woo, S. E., Sims, C. S., Rupp, D. E., \& Gibbons, A. M. (2008). Development engagement within and following developmental assessment centers: Considering feedback favorability and self-assessor agreement. Personnel Psychology, 61, $727-760$.

Wood, R. E., \& Bandura, A. (1989). Impact of conceptions of ability on self-regulatory mechanisms and complex decision making. Journal of Personality and Social Psychology, 56, 407-415. 
